\title{
MAPA DE CONTORNO ESTRUTURAL DO TOPO DO BASALTO SUBJACENTE AO GRUPO BAURU NO ESTADO DE SÃO PAULO
}

\author{
Jair SANTORO* \\ Marcos MASSOLI*
}

\begin{abstract}
RESUMO
A Bacia do Paraná apresenta uma unidade litoestratigráfica, Formação Serra Geral, caracterizada por inúmeros derrames predominantemente basálticos, de idade jurocretácea. Uma reconstituição da antiga superfície do topo dos derrames constitui a finalidade deste trabalho.

A topografia da superfície basáltica mostra-se bastante irregular, com altos e baixos estruturais, com caimento para noroeste e sudoeste, onde atinge as cotas mais baixas, em torno de $150 \mathrm{~m}$.
\end{abstract}

\section{ABSTRACT}

The Serra Geral Formation of the Brazilian Paraná Basin is characterized predominantly by Early basaltic flows. The purpose of this paper is a reconstitution of the basaltic top surface in the São Paulo State.

This surface dipping northwestward and southeastward is unevem due to st uctural highs and lows.

\section{INTRODUÇÃO}

Este trabalho tem como finalidade a confecção de um mapa da topografia do topo do basalto da Formação Serra Geral (Fig. I), o qual permite a verificação do padrão estrutural dos derrames na área abrangida. Ele vem aprimorar o trabalho de FRANGIPANI (1962) através da introdução de modificações que puderam ser efetuadas devido ao aparecimento de novos dados relativos às perfurações de poços profundos realizadas tanto pelo Instituto Geológico como por firmas particulares.

\section{CONSTRUÇÃO DO MAPA}

Para a construção do mapa de contorno estrutural foram locadas no mapabase as cotas do topo do basalto obtidas com a perfuração de poços profundos, cujos dados foram levantados nos arqui- vos do Instituto Geológico e em trabalhos publicados pelo DAEE (Tabela I).

Também utilizaram-se no traçado das curvas os dados obtidos em afloramentos que constam de mapas geológicos, nos quais se podem determinar as cotas do contato entre o Grupo Bauru e a Formação Serra Geral.

Uma vez lançadas no mapa-base as cotas da superfície basáltica, foram traçadas as curvas de contorno estrutural, com intervalos de $25 \mathrm{~m}$, usando-se a mesma técnica empregada no traçado de curvas de nível em mapas topográficos.

Parte do traçado das curvas estruturais é inferida, uma vez que os dados disponíveis não são totalmente suficientes para representação mais precisa do comportamento do topo basáltico na escala adotada.

*Instituto Geológico - SAA - Caixa Postal 8772 - 01000 - São Paulo, SP - Brasil. 
Com relação às perfurações que não atravessaram todo o Grupo Bauru, os dados obtidos também puderam ser utilizados no traçado das curvas, uma vez que nesses locais o topo do basalto está a uma cota menor que aquela atingida pelas perfurações, sendo que os valores inferidos indicam a posição da curva a ser traçada. Por exemplo, se o valor da curva cresce da esquerda para a direita e um ponto cotado tem valor $<450$, todas as curvas com valores iguais ou maiores que 450 passarão à direita do referido ponto.

\section{IDENTIFICAÇÃO DAS ESTRUTURAS}

Para auxiliar na interpretação dos aspectos estruturais que aparecem na área abrangida pelo mapa, foram elaboradas quatro seções geológicas (Fig. 2), duas (A-B e C-D) com direção NW-SE e duas (E-F e G-H) com direção NE-SW (Fig. 1).

Como se pode observar nas referidas seções geológicas, ocorrem baixos estruturais nas regiões de Santa Fé do Sul, Jales, São José do Rio Preto, Lins e Sud Menucci, estando os altos estruturais em Três Fronteiras, Bálsamo, Irapuã, Andradina e Nova Granada.

$\mathrm{Na}$ região de Bauru-Piratininga ocorre um alto estrutural (A!to de Piratininga), determinado por falhas com direções principais NE e NW, constituindo blocos representados pelas formações Corumbataí, Pirambóia e Botucatu (FULFARO et alii, 1983). Nessa área não ocorre a Formação Serra Geral, estando os sedimentos do Grupo Bauru assentados diretamente sobre os arenitos da Formação Botucatu (área hachuriada da Fig. 1).

Do ponto de vista regional a topografia do topo do basalto apresenta mergulho dirigido para NW, constituindo uma grande dobra sinclinal cujo eixo está representado pelo rio Tietê.

$\mathrm{Na}$ porção W do Estado de São Paulo, região de Presidente Prudente, a superfície basáltica também comporta-se como um sinclinal, cujo eixo mostra-se com rumo NE-SW e mergulho $0,02^{\circ} \mathrm{pa}$ ra SW, passando pelas cidades de Mariápolis, Presidente Bernardes e Marabá
Paulista. Essa área é a mais deprimida da Bacia do Paraná, onde a altitude do topo basáltico é inferior a $150 \mathrm{~m}$. Para isso deve ter contribuído o peso da grande espessura de basalto aí existente (cerca de $1.500 \mathrm{~m}$ ), o que provocou uma subsidência dos sedimentos subjacentes (LEINZ, in FRANGIPANI, 1962). Nessa região formou-se, então, uma subbacia, a qual condicionou a deposição dos sedimentos do Grupo Bauru.

As cotas do topo do basalto subjacente ao Grupo Bauru apresentam valores compreendidos entre $900 \mathrm{~m}$, na região de São Carlos, e 210 m nas proximidades de Panorama, junto ao rio Paraná, o que dá um declive médio, para W, de $1,6 \mathrm{~m} / \mathrm{km}$.

$\mathrm{Na}$ região compreendida entre Guaiçara e Queiroz, a superfície basáltica constitui um baixo estrutural de forma alongada, com o eixo orientado na direção NE-SW, mergulho $0,02^{\circ} \mathrm{NE}$, com cota mínima em torno de $245 \mathrm{~m}$ (em Guaiçara). Já na região de Presidente Bernardes o basalto ocupa uma depressão de forma aproximadamente circular, com altitude mínima em redor de $140 \mathrm{~m}$. O mesmo tipo de estrutura ocorre na região de São José do Rio Preto, o que pode ter grande importância econômica uma vez que essas depressões fechadas, situadas no contato entre os sedimentos arenosos do Grupo Bauru e as rochas basálticas, podem constituir excelentes condições para o armazenamento de água subterrânea.

A origem dessas depressões estaria ligada à existência de um relevo tectônico, posteriormente modelado por erosão antes da deposição do Grupo Bauru.

A área compreendida pelas cidades de General Salgado, Monte Aprazível, Catanduva e Bilac apresenta superfície basáltica bastante suave, evidenciada pelo espaçamento das curvas estruturais, sendo que o declive verificado entre as cidades de Catanduva e Auriflama, situadas no sentido do mergulho geral das camadas, é de $0,6 \mathrm{~m} / \mathrm{km}$. De Catanduva a Jaboticabal, em direção à porção leste do mapa, o declive do topo do basalto é mais acentuado, da ordem de $2 \mathrm{~m} / \mathrm{km}$.

$\mathrm{Na}$ porção W-NW do mapa, entre Andradina e Araçatuba, distantes entre si cerca de $100 \mathrm{~km}$, o topo do basalto exi- 


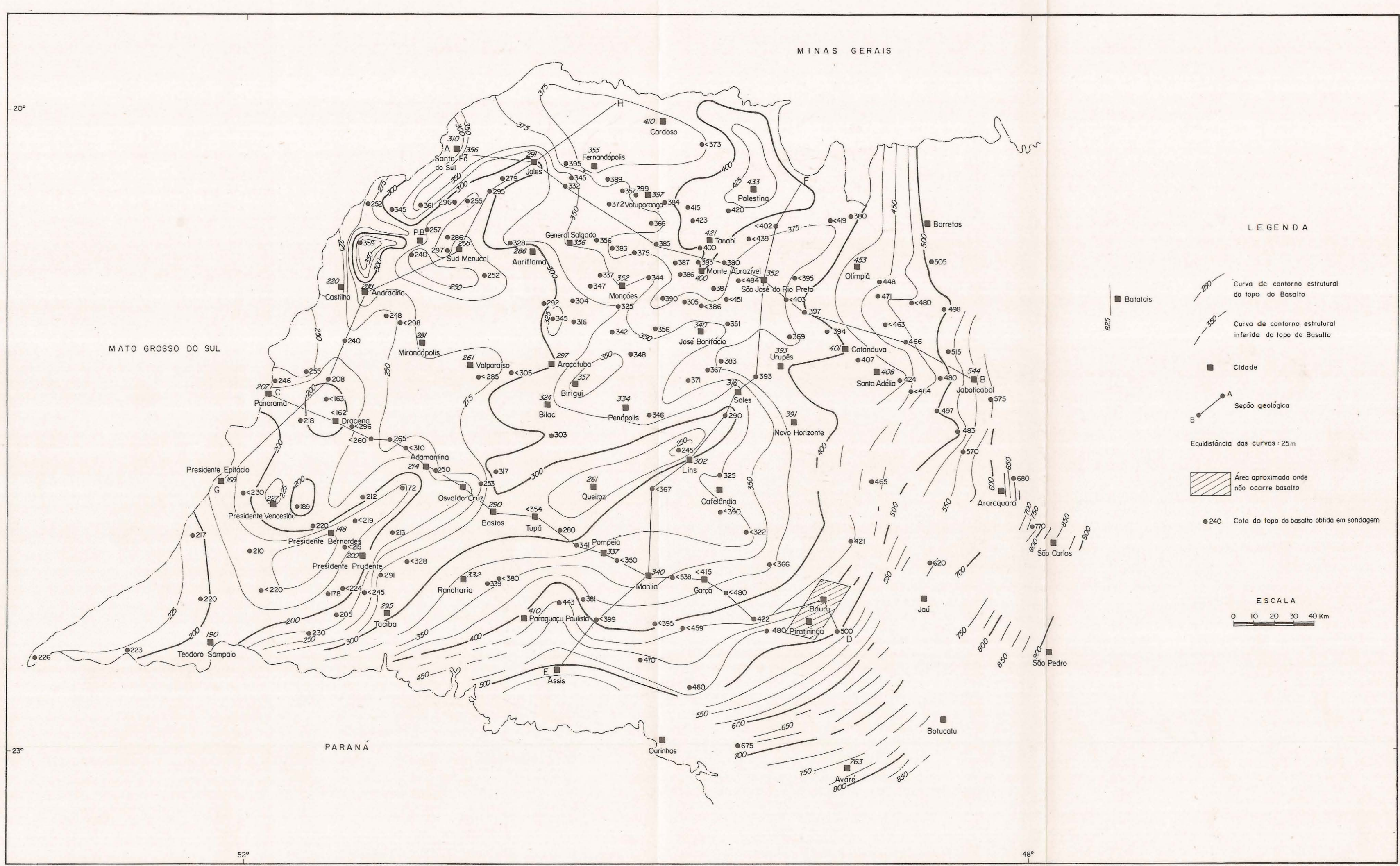
Fig. 1-MAPA DE CONTORNO ESTRUTURAL DO TOPO DO BASALTO SUBJACENTE AO GRUPO
BAURU NO ESTADO DE SÃO PAULO 


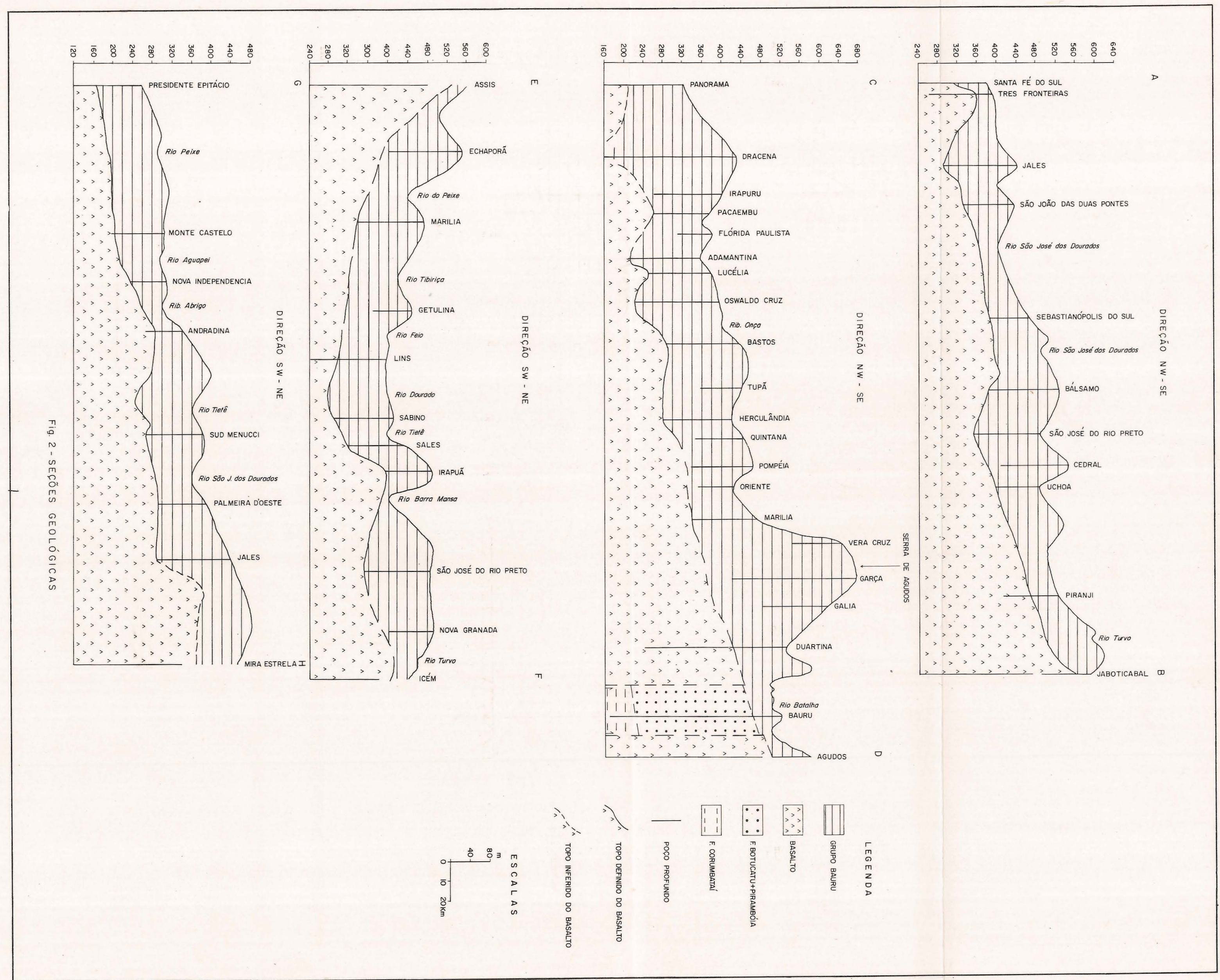


be relevo suave com desnível de apenas 9 $\mathrm{m}$ de Araçatuba para Andradina. Desta para Castilho, numa distância de $10 \mathrm{~km}$, a superfície basáltica torna-se mais ingreme, tendo um desnível de $68 \mathrm{~m}$. O basalto aflora $10 \mathrm{~km}$ a NW de Castilho, no vale do rio Paraná, próximo à $\mathrm{Hi}$ droelétrica de Jupiá, na cota de $260 \mathrm{~m}$, sofrendo, então, uma elevação altimétrica. Portanto a cidade de Castilho situase sobre uma bacia estrutural formada pelo topo da Formação Serra Geral.

\section{CONCLUSÕES}

Através do mapa de contorno estrutural elaborado, puderam ser tiradas as seguintes conclusões:

1 - No geral a superfície basáltica comporta-se como um sinclinal com eixo no sentido NW-SE e mergulho $\mathrm{O}, 04^{\circ} \mathrm{NW}$, correspondendo aproximadamente ao vale do rio Tietê;

2 - Na região de Presidente Bernardes verifica-se um sinclinal de amplitude menor que o anterior, porém com eixo no sentido NE-SW, com mergulho $\mathrm{O}, 02^{\circ} \mathrm{SW}$, onde o topo basáltico atinge a cota mais baixa $(148 \mathrm{~m})$, coincidindo com a área de maior espessura dos derrames basálticos da Bacia do Paraná;
3 - Dentre as depressões estruturais mais importantes destacam-se as de São José do Rio Preto, Lins, Jales e Sud Menucci, as quais podem constituir condições ideais para o armazenamento de água subterrânea;

4 - A altitude do topo do basalto subjacente ao Grupo Bauru varia de $900 \mathrm{~m}$, em São Carlos, a 148 m, em Presidente Bernardes;

5 - Na porção norte do mapa o declive da superfície basáltica é de $2 \mathrm{~m} / \mathrm{km}$, em direção a NW, entre as cidades de Jaboticabal e Catanduva. Desta em direção a Auriflama a declividade cai para $\mathrm{O}, 6$ $\mathrm{m} / \mathrm{km}$, formando um terraço estrutural. Em direção a Suzanópolis o topo basáltico se eleva, para em seguida diminuir em direção ao rio Paraná, constituindo um anticlinal com eixo de direção NE-SW;

6 - Na região de Assis o caimento do topo do basalto tem rumo aproximadamente norte;

7 - A área compreendida entre Bauru e Piratininiga, caracterizada por não apresentar basalto subaflorante, não pode ser melhor delimitada por falta de dados, embora se acredite que os seus limites não sejam muito diferentes dos estabelecidos no mapa.

TABELA 1 - Relação de poços cujos dados foram utilizados na elaboração do mapa estrutural do topo do basalto

Local

Adamantina

Adolfo

Agudos

Alfredo Marcondes

Altair

Álvares Machado

Alvinlândia

Américo Brasiliense

Andradina

Anhumas

Aparecida D'Oeste

Aparecida D'Oeste

Araçatuba

Araçatuba

Araçatuba (Vincentópolis)

Araçatuba (S. Ant. Aracanguá)

Araçatuba

Araçatuba

Araraquara (B. Andrade)

Araraquara

Arealva

\section{cota da boca}

do poço (m) cota do topo do basalto (m)

$\begin{array}{cr}355 & 214 \\ 445 & 367 \\ 576 & 500 \\ 415 & <219 \\ 564 & <419 \\ 435 & <215 \\ 580 & <459 \\ 720 & 80 \\ 348 & 288 \\ 445 & 245 \\ 398 & 296 \\ 400 & 255 \\ 391 & 316 \\ 372 & 345 \\ 398 & 304 \\ 387 & 292 \\ 375 & 297 \\ 337 & 252 \\ 678 & 600 \\ ? & 617 \\ 450 & 421\end{array}$


Rev. IG, São Paulo, 6(1/2):39-44, jan./dez. 1985

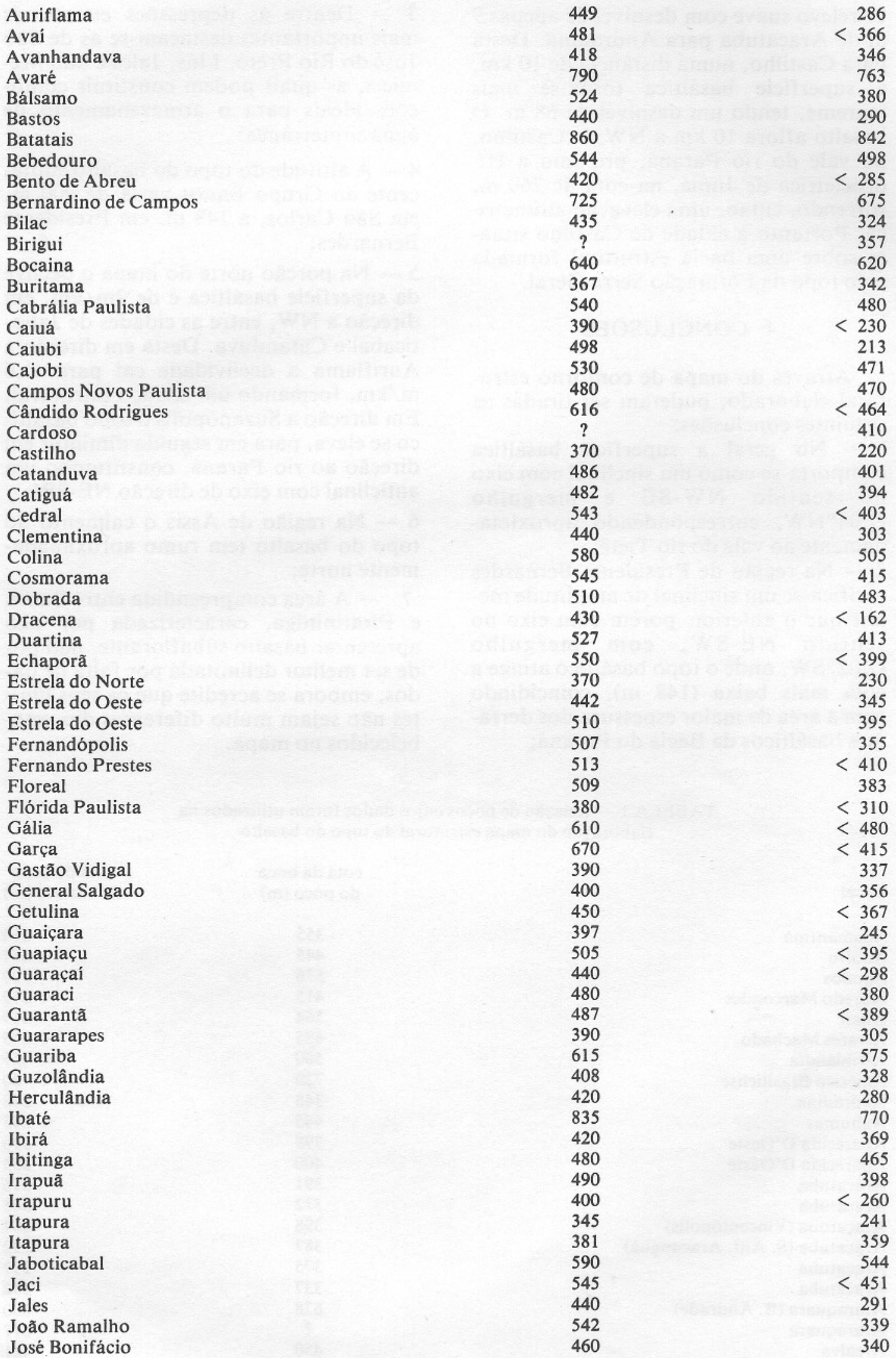


Rev. IG, São Paulo, 6(1/2):39-44, jan./dez. 1985

José Bonifácio

José Bonifácio 425

371

Junqueirópolis

Lucélia

Lutécia

Macaubal

Magda

Marabá Paulista

Mariápolis

Marília

Martinópolis

Matão

Mendonça

Meridiano

Meridiano (Vila Santo Antônio)

Mirandópolis

Mirante do Paranapanema

Mirante (Cuiabá Paulista)

Mirassol

Mirassolândia

Monções

Monte Alto

Monte Aprazivel (Eng. Balduíno)

Monte Aprazível

Monte Azul Paulista

Monte Castelo

Muritinga do Sul

Narandiba

Neves Paulista

Neves Paulista (Miraluz)

Nhandeara

Nipoã

Nova Granada

Nova Luzitânia

Nova Independência

Novo Horizonte

Ocauçu

Olímpia

Oscar Bressane

Osvaldo Cruz

Oriente

Pacaembu

Palestina

Palmeira D'Oeste

Panorama

Paraguaçu Paulista

Paraíso

Parapuã

Penápolis

Pereira Barreto

Pereira Barreto

Pereira Barreto

Pereira Barreto

Pereira (Lusanvira)

Pindorama

Piquerobi

Pirajuí

Piranji

Pirapozinho

Planalto

Planalto

Poloni

Pompéia 
Presidente Bernardes 381

Presidente Epitácio

Presidente Epitácio

Presidente Prudente

Presidente Venceslau

Quatá

Queiroz

Quintana

Rancharia

Rinópolis

Sabino

Sales

Salmourão

Santa Adélia

Santa Fé do Sul

Santo Anastácio

Santo Expedito

São Carlos

São Francisco

São João das Duas Pontes

São João do Pau D'Alho

São José do Rio Preto

São Pedro do Turvo

Sebastianópolis do Sul

Severinia

Sud Menucci

Sud Menucci

Sud Menucci

Taciba

Taiúva

Tanabi (Ecatu)

Tanabi (Ibiporanga)

Tanabi

Taquaritinga

Teodoro Sampaio

Teodoro Sampaio

Teodoro Sampaio (Rosana)

400

$367 \quad 297$

385

Três Fronteiras

Tupã

Tupi Paulista

Turiúba

Uchoa

União Paulista

Urupês

Valentim Gentil

$480 \quad 390$

$440-393$

$460 \quad 399$

Valentim Gentil

520

Valparaíso

405

Vera Cruz

Votuporanga

\section{REFERÊNCIAS BIBLIOGRÁFICAS}

DAEE 1976 Estudo de águas subterrâneas nas regiões administrativas 7, 8 e 9 Bauru, São José do Rio Preto e Araçatuba. São Paulo. v.4.

1979 Estudo de águas subterrâneas nas regiōes administrativas 10 e 11 Presidente Prudente e Marília. São Paulo. v.2.

FRANGIPANI, A. 1961/1962 Mapa da superfície superior do basalto subjacente aos arenitos cretáceos no Estado de São Paulo. O IGG: Revista do Instituto Geográfico e Geológico, São Paulo, 15 (n. ${ }^{\circ}$ único): 67-72.

FULFARO, V. J.; SANTOS, P.R. dos; SAAD, A.R. 1983 A estrutura de Piratininga. In: SIMPÓSIO REGIONAL DE GEOLOGIA, $4 .^{\circ}$, São Paulo, 1983. Boletim de resumos. São Paulo, SBG. Núcleo de São Paulo. p. 19 INSTITUTO GEOLÓGICO Cadastro de poços. 